\title{
Review Article \\ Fetal Nucleic Acids in Maternal Circulation: A Genetic Resource for Noninvasive Prenatal Diagnosis
}

\author{
Monisha Banerjee and Deepika Misra \\ Molecular \& Human Genetics Laboratory, Department of Zoology, University of Lucknow, Lucknow 226007, India \\ Correspondence should be addressed to Monisha Banerjee; mhglucknow@yahoo.com
}

Received 30 May 2012; Accepted 31 July 2012

Academic Editors: C. Walss-Bass, A. Yamamoto, and A. Zamborlini

Copyright (C) 2013 M. Banerjee and D. Misra. This is an open access article distributed under the Creative Commons Attribution License, which permits unrestricted use, distribution, and reproduction in any medium, provided the original work is properly cited.

\begin{abstract}
Invasive prenatal diagnosis (PND) holds a multitude of psychological considerations for women, their partners, family and community as a whole. Earlier, the non-invasive screening methods for certain disorders were serum analytes or ultrasound with low sensitivity and high false positivity. The discovery of fetal DNA in maternal plasma has opened up an approach for noninvasive PND (NIPD). Presence of fetal cells and cell-free fetal DNA (cffDNA) in the blood of pregnant women has been accepted universally and constant efforts are being made to enrich fetal DNA from maternal blood/plasma. Real-time quantitative polymerase chain reaction (qrt-PCR) has enabled fetal DNA to serve as a marker for chromosomal abnormalities, for example, trisomy 21 , preterm labor, and preeclampsia. In India, PND is provided in few centers since invasive methods require trained gynecologists, this limits investigation and therefore NIPD with cffDNA from mother's blood will revolutionize fetal medicine. The present paper deals with the latest developments in procurement of cffDNA, the probable source and enrichment of fetal DNA in maternal plasma, and the current status of its detection methodologies, applications, and its potential to be used as a powerful diagnostic tool.
\end{abstract}

\section{Introduction}

The frequency of inherited disorders database (FIDD) contains a total of 1580 records, classified into 14 groups of inherited disorders, of which information on 280 conditions comprising of 109 autosomal dominant, 136 autosomal recessive, and $35 \mathrm{X}$-linked disorders is currently available. There are also 19 groups of less well-defined conditions such as "inherited neuromuscular disorders" or "hemophilias" [1]. The only solution to diagnose such genetic disorder is prenatal diagnosis (PND). PND had its beginning in 1966, when Steele and Breg showed that the chromosome constitution of a fetus could be determined by analysis of cultured cells from amniotic fluid [2]. Later with the advent of molecular techniques, mutation and carrier analysis was performed by obtaining fetal tissue using invasive methods such as chorionic villus sampling (CVS), placental tissue, and amniocentesis [3]. Genetic disease in a family involves a great deal of anxiety such as having an affected child, lifelong morbidity, risk of miscarriage, and dilemma of taking the correct decision (Table 1) [4]. Nucleic acids (DNA and RNA) in the blood were observed $>60$ years ago as early as
1948, when Mandel and Metais reported the presence of cell free DNA (cfDNA) and RNA (cfRNA) in blood plasma of healthy and sick individuals [5-7]. Unfortunately, their work went unnoticed due to lack of clear understanding about cell free nucleic acids (cfNAs). Increased quantities of cfDNA were also observed in the plasma of cancer patients; for for example, pancreatic cancer [8]. The presence of fetal cells and cffDNA in the blood of pregnant women has been accepted universally. It is known that 3-6\% of maternal plasma DNA is cffDNA which has $100 \%$ detection rate [9-11]. An attempt has been made to review the developments till date by various groups in obtaining cell-free fetal nucleic acids (cffNAs) from maternal blood, its probable source, methods of detection, and applications in non-invasive prenatal diagnosis (NIPD) for a variety of genetic disorders.

\section{Source of Cell-Free Fetal Nucleic Acids (cffNAs) in Maternal Circulation}

Circulation of cffDNAs was demonstrated within maternal plasma and serum from healthy pregnant women, in surprisingly high mean concentrations of 3.4 and $6.2 \%$ of total 
TABLE 1: Risk of miscarriage in invasive methods of PND.

\begin{tabular}{|c|c|c|c|}
\hline Invasive test for prenatal diagnosis & $\begin{array}{l}\text { Sample taken } \\
\text { through }\end{array}$ & $\begin{array}{l}\text { Gestation time at which } \\
\text { procedure performed }\end{array}$ & $\begin{array}{c}\text { Risk of } \\
\text { miscarriage }\end{array}$ \\
\hline Chorionic villus Sampling (CVS) or choriocentesis & $\begin{array}{l}\text { Abdomen or } \\
\text { vagina }\end{array}$ & $11-13$ weeks & $<1 \%(1.9)$ \\
\hline Amniocentesis or amniotic fluid test (AFT) & Abdomen & 9-18 weeks & $<1 \%(1.4)$ \\
\hline $\begin{array}{l}\text { Cordocentesis or percutaneous umbilical cord blood } \\
\text { sampling (PUBS) }\end{array}$ & Abdomen & 18-20 weeks & $\sim 2 \%$ \\
\hline
\end{tabular}

plasma DNA and 0.13 and $1.0 \%$ of total serum DNA in early and late pregnancies, respectively $[9,12]$. An increase in the number of fetal cells was demonstrated in the blood of pregnant women who were carrying aneuploid fetuses [13]. Since then, analysis of fetal DNA in maternal plasma has been introduced as a new method for NIPD. There are three possible sources of fetal DNA in maternal circulation: (a) direct transfer of DNA, (b) placenta, and (c) haematopoietic cells.

Placenta is no longer thought to be an impermeable membrane since fetal DNA/RNA circulates freely in maternal plasma. Since a rapidly growing fetus and placenta have "tumor-like" characteristics cffNA of fetal origin can be expected to be found in maternal circulation $[11,14]$.

Presence of fetal RNA in the plasma of pregnant women was shown through the mRNA detection of a gene on the Y chromosome $[15,16]$. The detection rates of plasma fetal RNA in early and late pregnancies were 22 and 63\%, respectively $[9,15,17]$. Plasma fetal RNA analysis provided valuable information regarding gene expression in fetal tissues as in case of pregnancies with preeclampsia where abnormal patterns were observed [15]. Cell free fetal RNA (cffRNA) was not expected to be present in plasma due to the presence of RNAses. However, it was shown by detection of human placental lactogen (hPL) and $\beta$-hCG (human chorionic gonadotropin) mRNAs that the placenta was a major source of fetal-derived RNA [18]. A microarray-based approach was developed for systematic identification of placental mRNA markers such as the one transcribed from placental-specific 4 gene (PLAC4) located on chromosome 21, which could be detected in maternal plasma [19]. Subsequently, it was postulated that the placental-expressed mRNAs were encapsulated within a syncytiotrophoblast-derived microvesicle (STBM), which gave RNase resistance to "free" fetal RNA in maternal plasma [20]. Thus, with the development of RNA markers, analysis of maternal plasma allowed the noninvasive monitoring of fetal gene expression in a multitude of physiological and pathological conditions [21].

The various possible pathways by which cfDNA/cfRNA is released into circulation have been shown in Figure 1. Although evidence of high levels of circulating DNA and RNA in plasma of patients is increasing day by day, the actual origin of cffNA is still not clear [22]. The cffDNA rapidly disappears from the maternal circulation following childbirth with one exception in case of maternal liver disease where significant levels of fetal DNA were seen even after parturition $[16,23]$. A proper understanding of these issues will help in identifying the clinical applications of cffNAs.
2.1. Concentration of Fetal DNA in Maternal Plasma. The fractional concentration of cffDNA in maternal plasma is determined by the ratio of absolute concentration of cffDNA to absolute concentration of total (maternal and fetal) cfDNA. The concentration of cffDNA in maternal plasma was significantly higher in pregnant women compared to controls, median genome equivalent (GE) was 3.186 and 0.595 respectively $(P=0.001)$. This increased amount of cffDNA independent of previous pregnancies could be utilized for PND [24, 25]. There is significant correlation between early gestation age and total DNA concentration with a mean increase of $29.3 \%$ fetal DNA every week [26, 27]. Selective enrichment of fetal DNA requires targeting its unique characteristics that are different from maternal DNA [28]. Thus, the fractional concentration of cffDNA can be increased through selective enrichment of fetal DNA or through suppression of the background maternal DNA [22]. The three major approaches are shown below:

(A) $\%$ of fetal DNA = fetal DNA/maternal DNA + Fetal DNA,

(B) Increased \% of fetal DNA = increased Fetal DNA/ maternal DNA + Fetal DNA,

(C) Increased \% of fetal DNA = fetal DNA/decreased maternal DNA + fetal DNA.

2.2. Size Distribution of Maternal and Fetal DNA. The specific characteristic of fetal DNA in maternal plasma is the size of cffDNA, which is smaller than the corresponding maternal DNA. The median percentages of plasma DNA with size $>201$ bp were 57 , and $14 \%$ respectively, in pregnant and nonpregnant women $(P<0.001)$. The fetal-derived fragments were shorter than the maternal ones, $80 \%$ being $<193$ bp and $90 \%<313$ bp [29, 30]. Size fractionation of circulating DNA indicated that major portion of cffDNA was $<0.3 \mathrm{~kb}$, whereas maternally derived sequences were $>1 \mathrm{~kb}$. Analysis of size-fractionated DNA $(<0.3 \mathrm{~kb})$ from maternal plasma samples facilitated the ready detection of paternally and maternally inherited microsatellite markers. The size fractionation method is based on agarose gel electrophoresis followed by DNA extraction from manually cut agarose gel slices containing factors of different sizes [28]. This method was applied for the detection of paternally inherited fetal mutations [31]. However, the need for automated size fractionation methods such as microfluidics digital PCR was felt for its practical use in NIPD [22]. It revealed $\sim 3.1$ times higher fraction of fetal DNA than conventional nondigital real-time PCR [32]. 


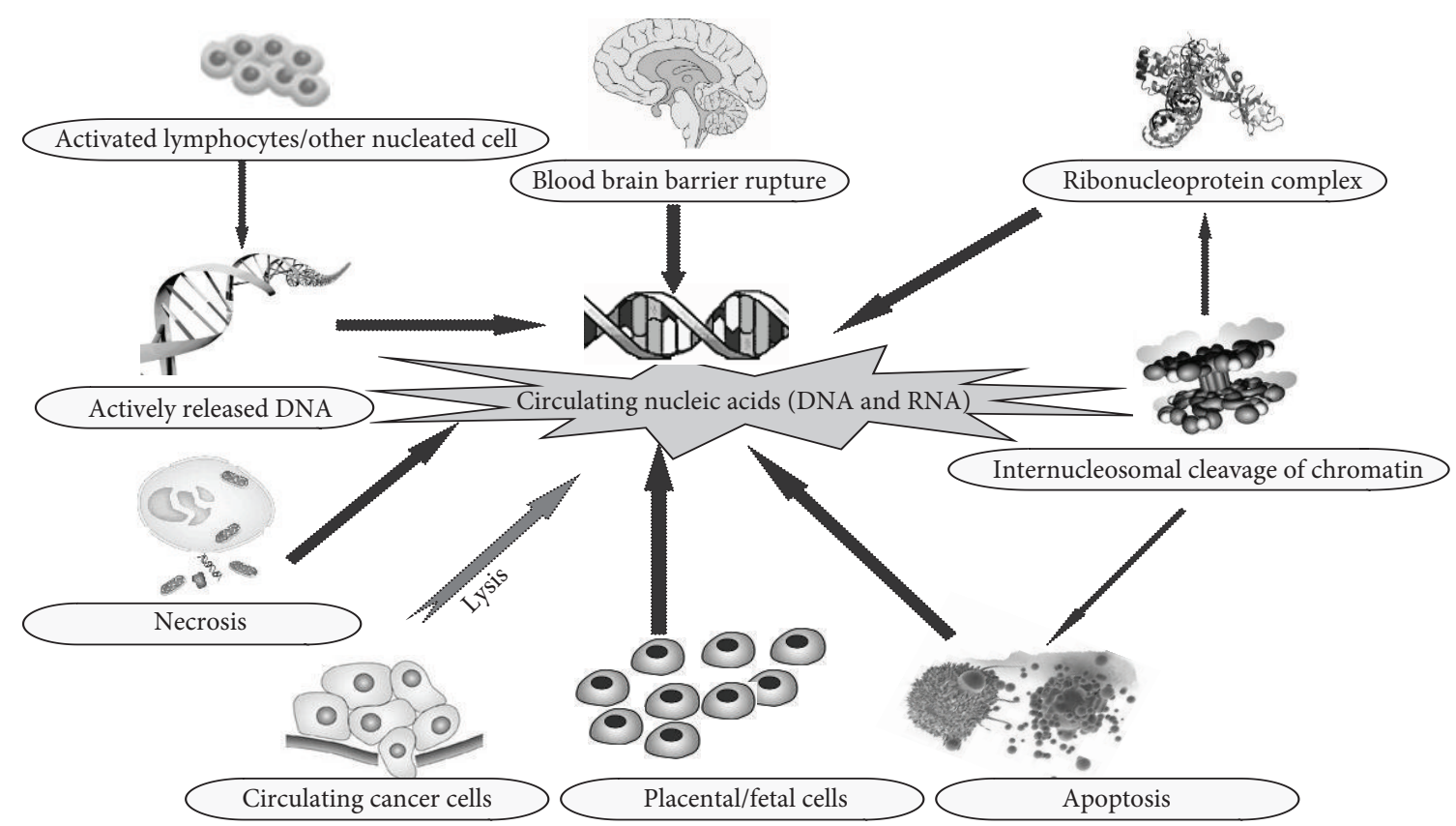

FIGURE 1: Schematic representation of various pathways by which nucleic acids are released into circulation [14].

\section{Detection of cffNA in Maternal Circulation}

DNA upto picogram concentrations can be detected using PCR. Earlier SRY markers were used for detection of cffDNA in maternal plasma [10]. However, with the advent of molecular techniques, various strategies have been developed, the list of fetal-specific markers has expanded from sex-dependent Y chromosomal sequences [33] and paternally inherited polymorphic markers [34-37], universal fetal markers such as placental-specific mRNA transcripts [18, 19, 37] and placental-specific epigenetic signatures [38-40]. Presently, real-time quantitative PCR is used for amplifying and quantifying the circulating DNA/RNA of interest [41, 42]. Light-cycler based real-time PCR is rapid, eliminates carry-over contamination problems and does not require post-PCR processing [43]. Total plasma circulating nucleic acids (DNA+RNA) can be detected using SYBR Green II dye [44]. The feto-maternal trafficking is a bidirectional process [45], therefore epigenetic markers may also have a role in the investigation of DNA transfer from mother to fetus [46, 47]. The measurement of plasma mRNA markers has provided a gender-independent approach for noninvasive prenatal gene expression profiling and has opened up numerous research and diagnostic possibilities.

3.1. Fetal DNA Detection by Y-Specific STR Markers. The presence of cffDNA in plasma of healthy pregnant women was showed in 1997 and confirmed by real-time PCR of Ychromosome-specific SRY sequences $[11,48]$. Several reports have confirmed positive correlation of fetal DNA concentration with gestational age. There is a slow increase in the first trimester which is raised by second and third trimesters $[9,49]$. The amplification sensitivity of Y-specific STRs and DYS19 sequences was 100\% in male fetal samples, while STRs
DYS385 and DYS392 were 91\% each [16]. However, sensitivity of STRs might be lowered with maternally inherited alleles. Therefore, cffDNA enabled the early detection of fetal sex so that further invasive tests could be avoided in case of $\mathrm{X}$-linked diseases such as haemophilia, Duchenne muscular dystrophy, X-linked mental retardation, adrenoleukodystrophy, Alport's syndrome, X-linked severe immunodeficiency, retinitis pigmentosa, $\mathrm{X}$-linked hydrocephalus, anhidrotic ectodermal dysplasia, Hunter's syndrome, Menkes syndrome, Lesch-Nyhan syndrome, and congenital adrenal hyperplasia (CAH) [10, 50].

3.2. Fetal RhCE Genotyping. Fetal Rh genotyping using cffDNA in maternal plasma was reported as a better source for prenatal diagnosis. NIPD of several conditions were achieved with this approach including fetal rhesus D status [51], myotonic dystrophy [52], achondroplasia [33], and certain chromosomal translocations $[53,54]$. The flow chart in Figure 2 shows in detail the strategy to be undertaken for prenatal screening of potential fetal RhD incompatibility in pregnant women [39]. The collective precision of noninvasive fetal genotype for $\mathrm{RhC/c}$ and $\mathrm{RhE} / \mathrm{e}$ determination using maternal peripheral blood was 96.3 and $98.2 \%$, respectively. This can safely replace the current methods used in the management of $\mathrm{RhC/c}$ or $\mathrm{RhE} / \mathrm{e}$ alloimmunised pregnancies [55].

3.3. Differential DNA Methylation of Maternal and Fetal DNA. Epigenetics is the study of molecular phenomenon that affects gene expression, but does not involve a change in DNA sequence [22]. The best studied epigenetic phenomenon is the process of DNA methylation, which involves addition of methyl groups to cytosine residues in the DNA sequence. 


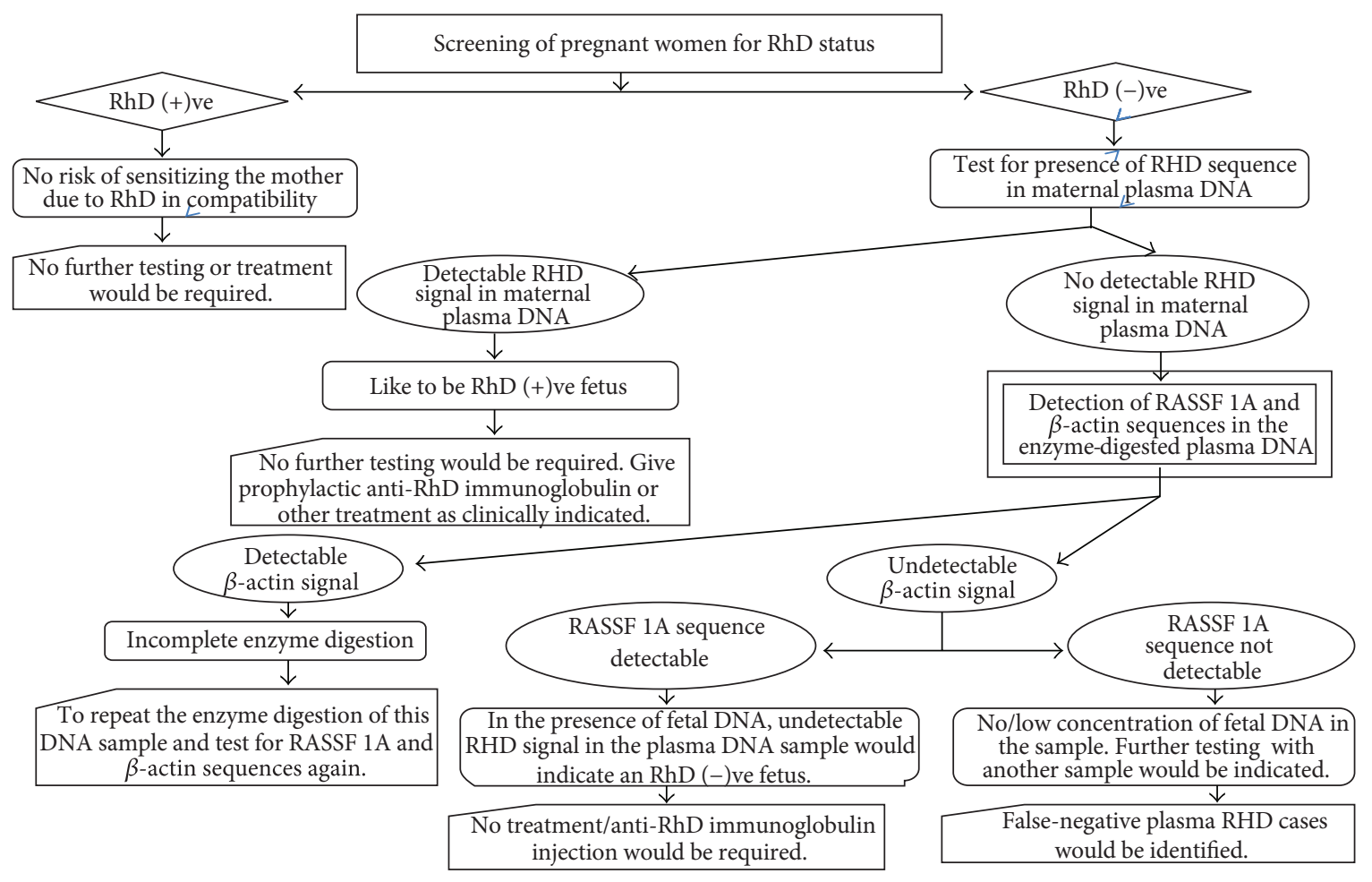

FIGURE 2: A schematic diagram showing logistics and results of prenatal screening for potential fetal RhD incompatibility in pregnant women [40].

It is known that if such cytosine methylation occurs in the promoters of genes, gene expression may be switched off, such as in certain tumor suppressor genes [56].

As the amount of fetal DNA is currently determined by quantifying Y-chromosome-specific sequences, alternative approaches such as the measurement of total cfDNA or the use of gender-independent fetal epigenetic markers, such as DNA methylation, offer a promising alternative [57]. The status of differentially methylated region in human IGF2H19 locus and single nucleotide polymorphism (SNP) was maintained such that paternal and maternal alleles were methylated and unmethylated, respectively [58]. Methylation was ascertained by bisulfite conversion and PCR using methylation-specific primers (MSP) for detecting paternally and maternally inherited fetal alleles in maternal plasma [59]. Differentially methylated fetal alleles were detected in maternal plasma by direct sequencing and primer-extension assay [46]. The strategy for epigenetic detection of fetal DNA has been illustrated in Figure 3.

The feasibility of epigenetic markers for fetal DNA detection in maternal plasma opened up a new approach for the development of gender and polymorphism-independent fetal markers. The epigenetic analysis of maternal plasma has obvious applications to disorders associated with genomic imprinting such as Prader-Willi syndrome and certain chromosomal aneuploidies associated with methylation abnormalities [60-62]. Till date, the diagnosis of fetal Down syndrome (trisomy 21) was carried out by obtaining fetal tissue using invasive procedures since NIPD of chromosomal aneuploidies was complicated due to the presence of coexisting background maternal DNA [63]. The discovery of $22 \mathrm{CpG}$ islands (CGIs) containing $255 \mathrm{CpG}$ sites on chromosome 21 indicated that epigenetic differences could be exploited for the development of markers for circulating fetal DNA [64]. The bisulfite-based approach increased the number of applicable $\mathrm{CpG}$ sites by 5 -folds compared to HpaII-based approach [65]. The epigenetic signatures of placental DNA have the desirable feature of being widespread in the human genome (22 of 114, 19.3\% analyzed CGIs on chromosome 21). Trisomy 21 could be detected either by analysis of epigenetic allelic ratios or direct comparison with a placenta-specific DNA methylation marker on a reference chromosome [39]. A combination of markers based on both fetal RNA and DNA may pave way for the development of a NIPD test for trisomy 21 that would be applicable to almost all fetomaternal pairs in the general population [64].

Another fetal epigenetic marker, RASSF1 (Ras association (RalGDS/AF-6) domain family 1) was found to be hypermethylated in placenta but completely unmethylated in maternal blood cells [66]. The placental methylated form, M-RASSF1, was developed as a universal marker for fetal DNA in maternal plasma [40]. On the basis of these epigenetic differences, Chim et al. [64] developed 2 novel fetal-DNA markers, $\mathrm{U}-P D E 9 A$ and U-CGI137 that were pregnancy specific in maternal plasma and rapidly cleared from the circulation upon delivery of fetus. These markers were independent of 


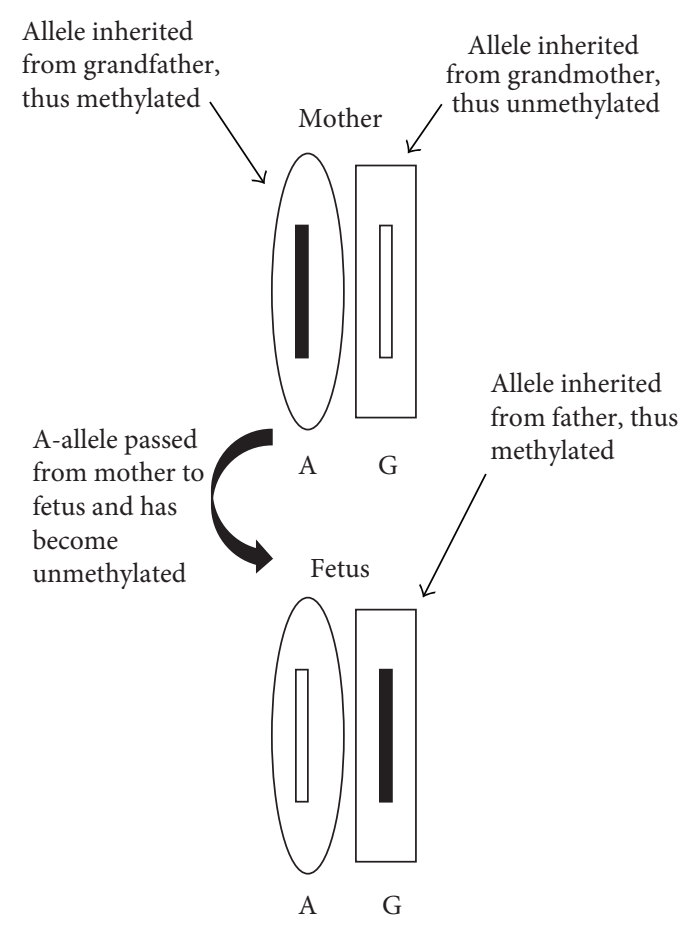

(a)

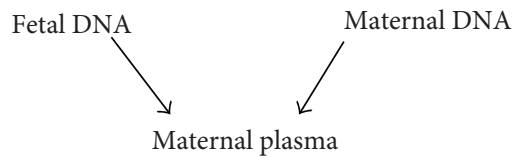

Mixture of fetal (minority) and maternal DNA (majority)

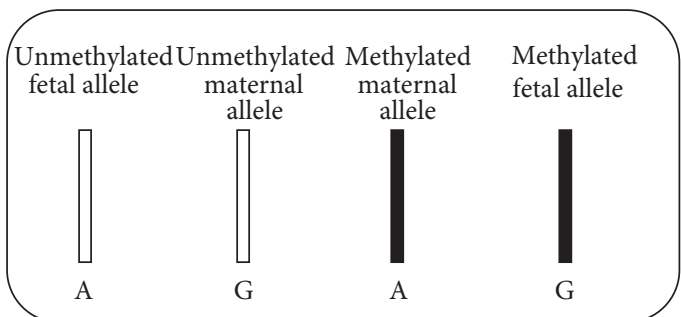

Bisulfite conversion Bisulfite conversion

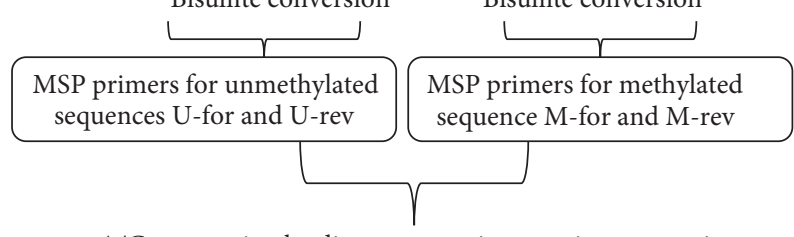

A/G genotyping by direct sequencing or primer extension

(b)

FIgURE 3: Strategy for the epigenetic detection of fetal DNA [46] (a) schematic diagram showing the difference in methylation status of the studied region in the IGF2-H19 locus (depending on origin of parents); (b) schematic diagram showing the detection of differentially methylated fetal alleles in maternal plasma. The region is methylated when inherited from father and unmethylated when inherited from mother. Methylated sequences are denoted by filled bars, whereas unmethylated sequences are denoted by open bars. $\mathrm{A} / \mathrm{G}$ denotes the respective allele of the SNP. fetal sex and genotype and hence could be applied to all fetomaternal pairs for NIPD of fetal sequences on chromosome 21 [64].

Methylation-sensitive restriction endonucleases are commonly used to digest hypomethylated DNA while the hypermethylated molecules remain intact for detection. Detection of the enzyme-digested placenta derived hypomethylated SERPINB5 (serpin peptidase inhibitor, clade B (ovalbumin), member 5; also known as maspin) molecules was achieved by performing stemloop extension followed by real-time PCR. Hypomethylated maspin was suggested as the first universal marker for fetal DNA [38]. The placental origin of stem-loop-extended SERPINB5 molecules was confirmed by genotyping. Enzyme digestion was performed by HpaII, a methylation-sensitive restriction endonuclease that recognizes and cuts at CCGG whose action would be blocked by CpG methylation. The major approaches have been shown in Figure 4. Since SERPINB5 is located on chromosome 18, the dosage of fetal chromosome 18 could be assessed by the ratio of polymorphic alleles of fetus-derived placental unmethylated form, U-SERPINB5, which is unlike the ratios in unaffected pregnancies [67]. This stem-loop technique was a major advancement in methylation studies since the protocol did not involve bisulfite treatment and allowed a selective amplification of fragmented DNA molecules produced by restriction digestion [68] and also hypomethylated placental DNA molecules in maternal plasma were preferentially amplified [69].

3.4. Determination of Fetal Aneuploidy by Allelic Ratio Discrimination. In a series of developments since 2000, plasma RNA was been established as a prenatal diagnostic tool. The plasma RNA was surprisingly stable, possibly through protection by particulate matter [70,71]. The comparative quantification of allelic SNPs arising from the same gene could be used to assess chromosome copy number. Candidate genes were identified on chromosome 21 of which PLAC4 was most abundant and appeared to be polymorphic. Lo et al. [37] developed the RNA-SNP allelic ratio approach for determining the dosage of chromosome 21 in maternal plasma using PLAC4 mRNA (Figure 5). It has been further proposed that the SNPs associated with such candidate genes need to be different between mother and father in order to achieve allelic discrimination [16, 37]. However, one group showed that the expression of PLAC4 is unaltered in trisomy 21 fetuses [72].

This new, noninvasive source of fetal DNA was rapidly used for prenatal determination of fetal gender in sexlinked diseases [73], congenital adrenal-hyperplasia [74], and fetal $\mathrm{RhD}$ status in pregnancies involving $\mathrm{RhD}$-negative mothers [41]. This approach has also been used for the prenatal detection of mutations inherited from father and absent in mother, for example, betathalassaemia [34, 75]. The main limitation of RNA-SNP allelic ratio approach was that only the fetus heterozygous for an analysed SNP can be successfully diagnosed and approximately $45 \%$ of fetuses would be expected to be heterozygous. When this approach was used on an unknown sample, it was not known whether 
Placenta

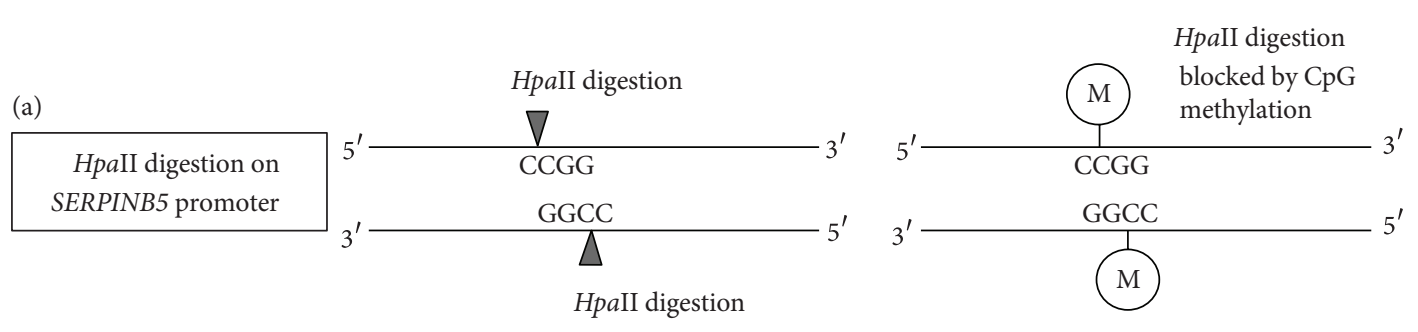

(b)<smiles>C1=CC=C1</smiles>

(c)

Stem-loop extension

Annealing of stemloop primer to the HpaII-digested DNA
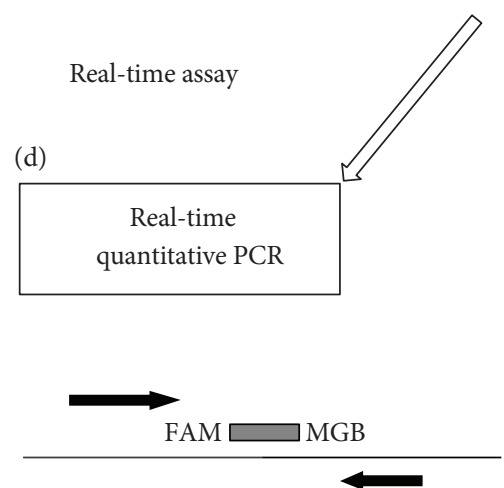

Amplicon size:

89 base pairs

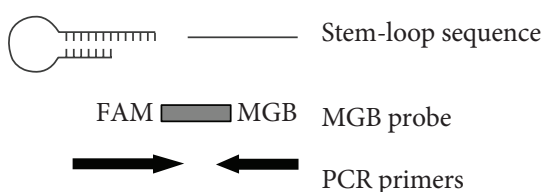

Maternal blood cells

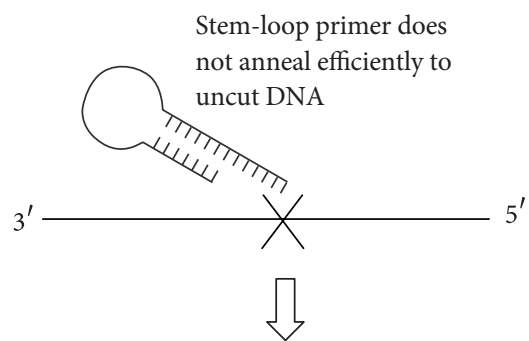

Inefficient stem-loop extension for long DNA
Genotyping assay

(e)

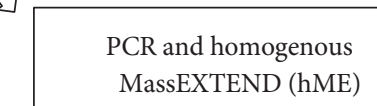

MassEXTEND (hME)

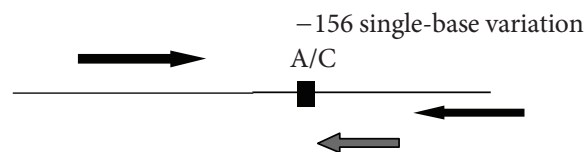

Amplicon size:

101 base pairs (excluding 10-mer tag)

FIGURE 4: Schematic diagram of the stem-loop assay design targeting the placenta-derived hypomethylated SERPINB5 promoter in maternal plasma [69].

the fetus was heterozygous for the analyzed SNP. In case of two SNP alleles, one could proceed to measure the SNP allelic ratio to determine whether the fetus was euploid or aneuploid [40].

The main disadvantage of the epigenetic approach over the RNA-SNP allelic ratio method was that many commonly used methods for DNA methylation analysis involved the use of bisulphite-based reagents $[22,68]$. Such reagents were shown to result in DNA degradation thereby reducing the amount of target DNA available for subsequent analysis [76]. However, the main advantage of the DNA methylation-based approach was that such markers were relatively abundant in the human genome [39].

\section{Applications of cffDNA}

In developing countries, chromosomal anomalies form the major cause of birth defects and mental retardation and are the leading cause of maternal and fetal/neonatal mortality and morbidity. All pregnancies carry a baseline risk of 3$4 \%$ for major congenital anomalies [77]. Analysis of circulating fetal DNA in maternal plasma is useful for NIPD 


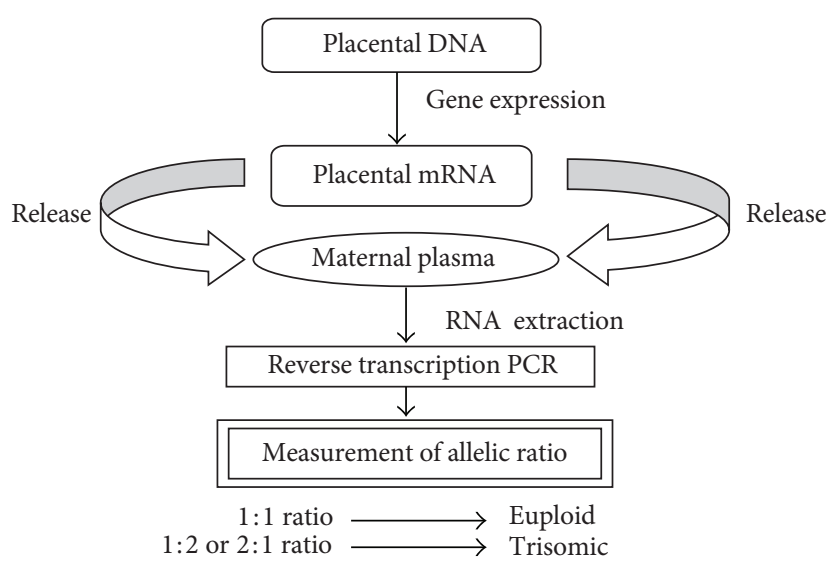

FIGURE 5: Diagrammatic representation of the RNA-SNP allelic ratio approach [37].

of chromosomal aneuploidies [37, 41], sex-linked disorders [74], $\beta$-thalassemia [35], fetal $\mathrm{RhD}$ status [78], preeclampsia $(\mathrm{PE})$, and detection of paternally inherited disease-causing sequences in maternal plasma [40].

It has been estimated that upto $80 \%$ of Down syndrome infants (Trisomy 21) are conceived by women under 35 years of age and is by far the most common disorder affecting approximately $1: 800$ pregnancies, although the probability increases with maternal age [78]. Over 95\% of pregnant women choose some form of prenatal screening and most of them consider serum-based screening tests [79]. Risk can be assessed by combining several factors, including (a) elevated or depressed serum levels of several biomarker proteins including $\beta$-hCG, $\alpha$-fetoprotein, PAPP-A (pregnancy associated plasma protein- $\mathrm{A}$ ), and inhibin $\mathrm{A},(\mathrm{b})$ maternal age and (c) increased nuchal translucency [16]. RT-PCR revealed that the concentration of fetal DNA was $97.5 \mathrm{GE} / \mathrm{mL}(29.2-187.0)$ for trisomy 13 cases and $31.5 \mathrm{GE} / \mathrm{mL}$ (18.6-77.6) for trisomy 18 in contrast to $40.3 \mathrm{GE} / \mathrm{mL}$ (3.7-127.4) for controls [80].

Preeclampsia is a multisystem disorder of pregnancy which is characterized by the onset of hypertension and proteinuria that develop after 20 weeks of gestation in previously normotensive women [81-83]. The early identification of patients with an increased risk for preeclampsia has been one of the most important goals in obstetrics [82]. Proteinuria is more closely associated with fetal growth restriction (FGR) or placental dysfunction [25]. However, the direct cause for preeclampsia is not identified and it may occur in any situation thereby complicating 3 to $5 \%$ of all pregnancies. It was found that fetal DNA concentration was elevated in the plasma of pregnant women with preeclampsia, the elevation being approximately double that of controls which regresses after delivery [84]. It was first reported that cffDNA increased approximately 5 -folds in the plasma of women with preeclampsia in third trimester in a small scale study of 20 each of preeclamptic women and gestational age-matched controls $[85,86]$. The same outcome was observed in second trimester with 10 preeclamptic women and 40 controls as well as in a large-scale study with 120 , each of pre-eclamptic women and controls $[87,88]$. The amount of cffDNA was routinely determined by quantifying Y-chromosome specific sequences [89]. Alternative approaches also showed an increase of total cfDNA in women with preeclampsia before onset and at term [90-92]. Recently, several multicentric studies are being conducted to confirm the predictive value of cffDNA for preeclampsia in combination with other potential markers, for example, P-selectin, PAPP-A, PP-13, sflt-1, sEng, PIGF. The $\beta$-globin values in maternal plasma are linked with the severity of preeclampsia as well, their levels being fivefolds higher than in controls [93].

\section{Conclusion}

Scientific and clinical status of the use of circulating cffNA technology for NIPD is a rapidly developing and dynamic field. Quantitative changes of cffDNA in maternal plasma have been reported in different studies using real timePCR for Y-chromosome specific sequences. There has been a constant effort to develop alternative approaches such as measurement of total cfDNA or use of gender-independent fetal epigenetic markers such as DNA methylation as well as cfRNA of placental origin. These offer a promising alternative for screening and prenatal diagnosis of genetic disorders. The presence of cffNAs in maternal circulation is a lowcost approach for the future development of novel strategies for NIPD as compared to invasive methods used for karyotyping and fluorescent in situ hybridization (FISH). The isolation and quantification methods of plasma/serum cffNA (DNA/RNA) are very critical in analyzing data. There is an urgent need for the standardization of techniques, careful evaluation and analysis of their specificity and sensitivity. In conclusion, efforts have to be made towards the establishment of standardized and simplified protocols for the analysis of cffNA biomarkers so that they can be used for routine obstetrics care in any clinical setup.

\section{Conflict of Interests}

The authors declare no conflict of interests.

\section{Authors' Contribution}

The authors contributed equally to this paper.

\section{Acknowledgments}

This study is dedicated to all mothers and their families. The authors are grateful to University Grant Commission, New Delhi, India for providing research grant and fellowship. Research grants from ICMR and DST to the Molecular and Human Genetics Lab, and from DST-FIST and DST-PURSE to the department are duly acknowledged.

\section{References}

[1] M. A. Alcántara, R. García-Cavazos, E. Hernández-U, A. González-Del Angel, A. Carnevale, and L. Orozco, "Carrier 
detection and prenatal molecular diagnosis in a duchenne muscular dystrophy family without any affected relative available," Annales de Genetique, vol. 44, no. 3, pp. 149-153, 2001.

[2] M. W. Steele and W. R. Breg, "Chromosome analysis of human amniotic-fluid cells," The Lancet, vol. 1, no. 7434, pp. 383-385, 1966.

[3] Thompson, and Thompson, Genetics in Medicine, WB Saunders, Philadelphia, Pa, USA, 7th edition, 2007.

[4] M. Mukherjee, G. S. Pandey, A. Kesari, S. R. Phadke, and B. Mittal, "Prenatal diagnosis of genetic disorders by molecular methods," Perinatology, vol. 6, no. 5, pp. 221-230, 2004.

[5] P. Mandel and P. Metais, "Les acides nucleiques du plasma sanguine chez I'homme," Comptes Rendus de l'Académie des Sciences, vol. 142, pp. 241-243, 1948.

[6] A. R. Thierry, F. Mouliere, C. Gongora et al., "Origin and quantification of circulating DNA in mice with human colorectal cancer xenografts," Nucleic Acids Research, vol. 38, no. 18, Article ID gkq421, pp. 6159-6175, 2010.

[7] M. Urbanova, J. Plzak, H. Strnad, and J. Betka, "Circulating nucleic acids as a new diagnostic tool," Cellular and Molecular Biology Letters, vol. 15, no. 2, pp. 242-259, 2010.

[8] S. A. Leon, B. Shapiro, D. M. Sklaroff, and M. J. Yaros, "Free DNA in the serum of cancer patients and the effect of therapy," Cancer Research, vol. 37, no. 3, pp. 646-650, 1977.

[9] Y. M. D. Lo, M. S. C. Tein, T. K. Lau et al., "Quantitative analysis of fetal DNA in maternal plasma and serum: implications for noninvasive prenatal diagnosis," American Journal of Human Genetics, vol. 62, no. 4, pp. 768-775, 1998.

[10] C. F. Wright and H. Burton, "The use of cell-free fetal nucleic acids in maternal blood for non-invasive prenatal diagnosis," Human Reproduction Update, vol. 15, no. 1, pp. 139-151, 2009.

[11] A. Cetin, "Cell-free fetal DNA and RNA circulating in maternal blood: review, part I," Basic and Clinical Sciences, vol. 52, no. 3, pp. 52-60, 2010.

[12] D. W. Bianchi, "Circulating fetal DNA: its origin and diagnostic potential-a review," Placenta, vol. 25, pp. S93-S101, 2004.

[13] D. W. Bianchi, J. M. Williams, L. M. Sullivan, F. W. Hanson, K. W. Klinger, and A. P. Shuber, "PCR quantitation of fetal cells in maternal blood in normal and aneuploid pregnancies," American Journal of Human Genetics, vol. 61, no. 4, pp. 822-829, 1997.

[14] V. Swarup and M. R. Rajeswari, "Circulating (cell-free) nucleic acids-a promising, non-invasive tool for early detection of several human diseases," FEBS Letters, vol. 581, no. 5, pp. 795-799, 2007.

[15] L. L. M. Poon, T. N. Leung, T. K. Lau, and Y. M. D. Lo, "Presence of fetal RNA in maternal plasma," Clinical Chemistry, vol. 46, no. 11, pp. 1832-1834, 2000.

[16] N. D. Avent, T. E. Madgett, D. G. Maddocks, and P. W. Soothill, "Cell-free fetal DNA in the maternal serum and plasma: current and evolving applications," Current Opinion in Obstetrics and Gynecology, vol. 21, no. 2, pp. 175-179, 2009.

[17] R. W. Chiu, R. Akolekar, Y. W. Zheng et al., "Non-invasive prenatal assessment of trisomy 21 by multiplexed maternal plasma DNA sequencing: large scale validity study," British Medical Journal, vol. 342, article c7401, 2011.

[18] E. K. O. Ng, N. B. Y. Tsui, T. K. Lau et al., "mRNA of placental origin is readily detectable in maternal plasma," Proceedings of the National Academy of Sciences of the United States of America, vol. 100, no. 8, pp. 4748-4753, 2003.
[19] N. B. Y. Tsui, S. S. C. Chim, R. W. K. Chiu et al., "Systematic micro-array based identification of placental mRNA in maternal plasma: towards non-invasive prenatal gene expression profiling," Journal of Medical Genetics, vol. 41, no. 6, pp. 461-467, 2004.

[20] A. K. Gupta, W. Holzgreve, B. Huppertz, A. Malek, H. Schneider, and S. Hahn, "Detection of fetal DNA and RNA in placentaderived syncytiotrophoblast microparticles generated in vitro," Clinical Chemistry, vol. 50, no. 11, pp. 2187-2190, 2004.

[21] J. L. Maron, K. L. Johnson, D. Slonim et al., “Gene expression analysis in pregnant women and their infants identifies unique fetal biomarkers that circulate in maternal blood," Journal of Clinical Investigation, vol. 117, no. 10, pp. 3007-3019, 2007.

[22] Y. M. D. Lo and R. W. K. Chiu, "Noninvasive prenatal diagnosis of fetal chromosomal aneuploidies by maternal plasma nucleic acid analysis," Clinical Chemistry, vol. 54, no. 3, pp. 461-466, 2008.

[23] M. Nelson, C. Eagle, M. Langshaw, H. Popp, and H. Kronenberg, "Genotyping fetal DNA by non-invasive means: extraction from maternal plasma," Vox Sanguinis, vol. 80, no. 2, pp. 112-116, 2001.

[24] T. Gozdziewicz, K. Gruca-Stryjak, P. Wirstlein, J. Kornacki, and J. Skrzypczak, "Free fetal DNA maternal plasma concentration as predictive factor of hypertensive disorders in pregnancy," Archives of Perinatal Medicine, vol. 15, pp. 17-20, 2009.

[25] A. Sekizawa, Y. Purwosunu, R. Matsuoka et al., "Recent advances in non-invasive prenatal DNA diagnosis through analysis of maternal blood," Journal of Obstetrics and Gynaecology Research, vol. 33, no. 6, pp. 747-764, 2007.

[26] A. Farina, E. Caramelli, M. Concu et al., "Testing normality of fetal DNA concentration in maternal plasma at 10-12 completed weeks' gestation: a preliminary approach to a new marker for genetic screening," Prenatal Diagnosis, vol. 22, no. 2, pp. 148-152, 2002.

[27] A. K. C. Chan, R. W. K. Chiu, and Y. M. D. Lo, "Cell-free nucleic acids in plasma, serum and urine: a new tool in molecular diagnosis," Annals of Clinical Biochemistry, vol. 40, no. 2, pp. 122-130, 2003.

[28] Y. Li, B. Zimmermann, C. Rusterholz, A. Kang, W. Holzgreve, and S. Hahn, "Size separation of circulatory DNA in maternal plasma permits ready detection of fetal DNA polymorphisms," Clinical Chemistry, vol. 50, no. 6, pp. 1002-1011, 2004.

[29] K. C. A. Chan, J. Zhang, A. B. Y. Hui et al., "Size distributions of maternal and fetal DNA in maternal plasma," Clinical Chemistry, vol. 50, no. 1, pp. 88-92, 2004.

[30] G. Vecchione, M. Tomaiuolo, M. Sarno et al., "Fetal sex identification in maternal plasma by means of short tandem repeats on chromosome X," Annals of the New York Academy of Sciences, vol. 1137, pp. 148-156, 2008.

[31] Y. Li, E. Di Naro, A. Vitucci, B. Zimmermann, W. Holzgreve, and S. Hahn, "Detection of paternally inherited fetal point mutations for $\beta$-thalassemia using size-fractionated cell-free DNA in maternal plasma," The Journal of the American Medical Association, vol. 293, no. 7, pp. 843-849, 2005.

[32] F. M. F. Lun, R. W. K. Chiu, K. C. A. Chan, T. Y. Leung, T. K. Lau, and Y. M. D. Lo, "Microfluidics digital PCR reveals a higher than expected fraction of fetal DNA in maternal plasma," Clinical Chemistry, vol. 54, no. 10, pp. 1664-1672, 2008.

[33] R. J. P. Rijnders, R. B. van der Luijt, E. D. J. Peters et al., "Earliest gestational age for fetal sexing in cell-free maternal plasma," Prenatal Diagnosis, vol. 23, no. 13, pp. 1042-1044, 2003. 
[34] H. Saito, A. Sekizawa, T. Morimoto, M. Suzuki, and T. Yanaihara, "Prenatal DNA diagnosis of a single-gene disorder from maternal plasma," The Lancet, vol. 356, no. 9236, p. 1170, 2000.

[35] R. W. K. Chiu, T. K. Lau, T. N. Leung, K. C. K. Chow, D. H. K. Chui, and Y. M. D. Lo, "Prenatal exclusion of $\beta$ thalassaemia major by examination of maternal plasma," The Lancet, vol. 360, no. 9338, pp. 998-1000, 2002.

[36] K. C. K. Chow, R. W. K. Chiu, N. B. Y. Tsui et al., "Mass spectrometric detection of an SNP panel as an internal positive control for fetal DNA analysis in maternal plasma," Clinical Chemistry, vol. 53, no. 1, pp. 141-142, 2007.

[37] Y. M. D. Lo, N. B. Y. Tsui, R. W. K. Chiu et al., "Plasma placental RNA allelic ratio permits noninvasive prenatal chromosomal aneuploidy detection," Nature Medicine, vol. 13, no. 2, pp. 218-223, 2007.

[38] S. S. C. Chim, Y. K. Tong, R. W. K. Chiu et al., "Detection of the placental epigenetic signature of the maspin gene in maternal plasma," Proceedings of the National Academy of Sciences of the United States of America, vol. 102, no. 41, pp. 14753-14758, 2005.

[39] Y. K. Tong, C. Ding, R. W. K. Chiu et al., "Noninvasive prenatal detection of fetal trisomy 18 by epigenetic allelic ratio analysis in maternal plasma: theoretical and empirical considerations," Clinical Chemistry, vol. 52, no. 12, pp. 2194-2202, 2006.

[40] K. C. A. Chan, C. Ding, A. Gerovassili et al., "Hypermethylated RASSF1A in maternal plasma: a universal fetal DNA marker that improves the reliability of noninvasive prenatal diagnosis," Clinical Chemistry, vol. 52, no. 12, pp. 2211-2218, 2006.

[41] K. Finning, P. Martin, J. Summers, E. Massey, G. Poole, and G. Daniels, "Effect of high throughput RHD typing of fetal DNA in maternal plasma on use of anti-RhD immunoglobulin in $\mathrm{RhD}$ negative pregnant women: prospective feasibility study," British Medical Journal, vol. 336, no. 7648, pp. 816-818, 2008.

[42] I. C. Kavanagh and S. C. Baker, "Advances in nucleic acid detection and quantification," Biochemical Society Transactions, vol. 37, no. 2, pp. e1-e4, 2009.

[43] M. Gueudin, J. C. Plantier, F. Damond, P. Roques, P. Mauclère, and F. Simon, "Plasma viral RNA assay in HIV-1 group O infection by real-time PCR," Journal of Virological Methods, vol. 113, no. 1, pp. 43-49, 2003.

[44] E. S. Morozkin, P. P. Laktionov, E. Y. Rykova, and V. V. Vlassov, "Fluorometric quantification of RNA and DNA in solutions containing both nucleic acids," Analytical Biochemistry, vol. 322, no. 1, pp. 48-50, 2003.

[45] D. W. Bianchi, "Fetomaternal cell trafficking: a story that begins with prenatal diagnosis and may end with stem cell therapy," Journal of Pediatric Surgery, vol. 42, no. 1, pp. 12-18, 2007.

[46] L. L. M. Poon, T. N. Leung, T. K. Lau, K. C. K. Chow, and Y. M. D. Lo, "Differential DNA methylation between fetus and mother as a strategy for detecting fetal DNA in maternal plasma," Clinical Chemistry, vol. 48, no. 1, pp. 35-41, 2002.

[47] C. Proudhon and D. Bourc'his, "Identification and resolution of artifacts in the interpretation of imprinted gene expression," Briefings in Functional Genomics, vol. 9, no. 5-6, pp. 374-384, 2010.

[48] Y. M. D. Lo, N. Corbetta, P. F. Chamberlain et al., "Presence of fetal DNA in maternal plasma and serum," The Lancet, vol. 350, no. 9076, pp. 485-487, 1997.

[49] F. Z. Bischoff, D. E. Lewis, and J. L. Simpson, "Cell-free fetal DNA in maternal blood: kinetics, source and structure," Human Reproduction Update, vol. 11, no. 1, pp. 59-67, 2005.
[50] R. Akolekar, D. H. Farkas, A. L. V. Agtmael, A. T. Bombard, and K. H. Nicolaides, "Fetal sex determination using circulating cell-free fetal DNA (ccffDNA) at 11 to 13 weeks of gestation," Prenatal Diagnosis, vol. 30, no. 10, pp. 918-923, 2010.

[51] S. Illanes, S. A. Fattah, and P. Soothill, "Review non-invasive prenatal diagnosis," Obstetrics and Gynecology, vol. 8, no. 2, pp. 91-95, 2006.

[52] P. Amicucci, M. Gennarelli, G. Novelli, and B. Dallapiccola, "Prenatal diagnosis of myotonic dystrophy using fetal DNA obtained from maternal plasma," Clinical Chemistry, vol. 46, no. 2, pp. 301-302, 2000.

[53] C. P. Chen, S. R. Chern, and W. Wang, "Fetal DNA in maternal plasma: the prenatal detection of a paternally inherited fetal aneuploidy," Prenatal Diagnosis, vol. 20, no. 4, pp. 355-357, 2000.

[54] C. P. Chen, S. R. Chern, and W. Wang, "Fetal DNA analyzed in plasma from a mother's three consecutive pregnancies to detect paternally inherited aneuploidy," Clinical Chemistry, vol. 47, no. 5, pp. 937-939, 2001.

[55] O. G. Holtzman, C. A. Grotegut, J. P. Gaughan, E. J. Holtzman, C. Floro, and E. Hernandez, "Noninvasive fetal RhCE genotyping from maternal blood," BJOG: An International Journal of Obstetrics and Gynaecology, vol. 116, no. 2, pp. 144-151, 2009.

[56] P. A. Jones and S. B. Baylin, "The epigenomics of cancer," Cell, vol. 128, no. 4, pp. 683-692, 2007.

[57] S. Hahn, C. Rusterholz, I. Hösli, and O. Lapaire, "Cell-free nucleic acids as potential markers for preeclampsia," Placenta, vol. 32, supplement 1, pp. S17-S20, 2011.

[58] C. H. Park, H. S. Kim, S. G. Lee, and C. K. Lee, "Methylation status of differentially methylated regions at Igf2/H19 locus in porcine gametes and preimplantation embryos," Genomics, vol. 93, no. 2, pp. 179-186, 2009.

[59] Y.-K. Tong and Y. M. D. Lo, "Diagnostic developments involving cell-free (circulating) nucleic acids," Clinica Chimica Acta, vol. 363, no. 1-2, pp. 187-196, 2006.

[60] K. Pfeifer, "Mechanisms of genomic imprinting," American Journal of Human Genetics, vol. 67, no. 4, pp. 777-787, 2000.

[61] S. Chappell and L. Morgan, "Searching for genetic clues to the causes of pre-eclampsia," Clinical Science, vol. 110, no. 4, pp. 443-458, 2006.

[62] B. Crespi, "Genomic imprinting in the development and evolution of psychotic spectrum conditions," Biological Reviews, vol. 83, no. 4, pp. 441-493, 2008.

[63] Z. Alfirevic, K. Sundberg, and S. Brigham, "Amniocentesis and chorionic villus sampling for prenatal diagnosis," Cochrane Database of Systematic Reviews, no. 3, Article ID CD003252, 2003.

[64] S. S. C. Chim, S. Jin, T. Y. H. Lee et al., "Systematic search for placental DNA-methylation markers on chromosome 21: toward a maternal plasma-based epigenetic test for fetal trisomy 21," Clinical Chemistry, vol. 54, no. 3, pp. 500-511, 2008.

[65] R. W. Old, F. Crea, W. Puszyk, and M. A. Hultén, "Candidate epigenetic biomarkers for non-invasive prenatal diagnosis of Down syndrome," Reproductive BioMedicine Online, vol. 15, no. 2, pp. 227-235, 2007.

[66] R. W. K. Chiu, S. S. C. Chim, I. H. N. Wong et al., "Hypermethylation of RASSF1A in human and rhesus placentas," American Journal of Pathology, vol. 170, no. 3, pp. 941-950, 2007.

[67] R. W. K. Chiu, L. L. M. Poon, T. K. Lau, T. N. Leung, E. M. C. Wong, and Y. M. D. Lo, "Effects of blood-processing protocols on fetal and total DNA quantification in maternal plasma," Clinical Chemistry, vol. 47, no. 9, pp. 1607-1613, 2001. 
[68] P. W. Laird, "Principles and challenges of genome-wide DNA methylation analysis," Nature Reviews Genetics, vol. 11, no. 3, pp. 191-203, 2010.

[69] Y. K. Tong, R. W. K. Chiu, T. Y. Leung et al., "Detection of restriction enzyme-digested target DNA by PCR amplification using a stem-loop primer: application to the detection of hypomethylated fetal DNA in maternal plasma," Clinical Chemistry, vol. 53, no. 11, pp. 1906-1914, 2007.

[70] E. K. O. Ng, N. B. Y. Tsui, N. Y. L. Lam et al., "Presence of filterable and nonfilterable mRNA in the plasma of cancer patients and healthy individuals," Clinical Chemistry, vol. 48, no. 8, pp. 1212-1217, 2002.

[71] N. B. Y. Tsui, E. K. O. Ng, and Y. M. D. Lo, "Stability of endogenous and added RNA in blood specimens, serum, and plasma," Clinical Chemistry, vol. 48, no. 10, pp. 1647-1653, 2002.

[72] I. Banzola, C. Rusterholz, L. Zannoni et al., "PLAC4 and $\beta$ HCG mRNA levels are not altered in the maternal circulation of pregnancies with trisomy 21," Prenatal Diagnosis, vol. 28, no. 13, pp. 1262-1267, 2008.

[73] J. M. Costa, A. Benachi, and E. Gautier, "New strategy for prenatal diagnosis of X-linked disorders," The New England Journal of Medicine, vol. 346, no. 19, article 1502, 2002.

[74] S. Z. A. Badawy, A. Etman, V. Cuenca, A. Montante, and L. Kaufman, "Fetal sex determination from maternal plasma in pregnancies at risk for congenital adrenal hyperplasia," Obstetrics and Gynecology, vol. 98, no. 3, pp. 374-378, 2001.

[75] C. Ding, R. W. K. Chiu, T. K. Lau et al., "MS analysis of singlenucleotide differences in circulating nucleic acids: application to noninvasive prenatal diagnosis," Proceedings of the National Academy of Sciences of the United States of America, vol. 101, no. 29, pp. 10762-10767, 2004.

[76] C. Grunau, S. J. Clark, and A. Rosenthal, "Bisulfite genomic sequencing: systematic investigation of critical experimental parameters," Nucleic Acids Research, vol. 29, no. 13, article E65, 2001.

[77] V. Bansal, S. Suresh, I. Suresh, S. Jagadeesh, and G. Fazal, "Genetic counseling in chromosomal abnormalities," Journal of Prenatal Diagnosis and Therapy, vol. 1, no. 1, pp. 14-19, 2010.

[78] C. Rösch, V. Steinbicker, and S. Kropf, "Down's syndrome: the effects of prenatal diagnosis and demographic factors in a region of the Eastern part of Germany," European Journal of Epidemiology, vol. 16, no. 7, pp. 627-632, 2000.

[79] T. Reynolds, "The triple test as a screening technique for Down syndrome: reliability and relevance," International Journal of Women's Health, vol. 2, no. 1, pp. 83-88, 2010.

[80] T. Wataganara, E. S. LeShane, A. Farina et al., "Maternal serum cell-free fetal DNA levels are increased in cases of trisomy 13 but not trisomy 18," Human Genetics, vol. 112, no. 2, pp. 204-208, 2003.

[81] C. W. Redman and I. L. Sargent, "Latest advances in understanding preeclampsia," Science, vol. 308, no. 5728, pp. 1592-1594, 2005.

[82] B. Sibai, G. Dekker, and M. Kupferminc, "Pre-eclampsia," The Lancet, vol. 365, no. 9461, pp. 785-799, 2005.

[83] E. B. Ndayambagye, M. Nakalembe, and D. K. Kaye, "Factors associated with persistent hypertension after puerperium among women with pre-eclampsia/eclampsia in Mulago hospital, Uganda," BMC Pregnancy and Childbirth, vol. 10, article 12, 2010.

[84] W. P. Robinson, M. S. Peñaherrera, R. Jiang et al., "Assessing the role of placental trisomy in preeclampsia and intrauterine growth restriction," Prenatal Diagnosis, vol. 30, no. 1, pp. 1-8, 2010.

[85] Y. M. D. Lo, T. N. Leung, M. S. C. Tein et al., "Quantitative abnormalities of fetal DNA in maternal serum in preeclampsia," Clinical Chemistry, vol. 45, no. 2, pp. 184-188, 1999.

[86] S. Sifakis, A. Zaravinos, N. Maiz, D. A. Spandidos, and K. H. Nicolaides, "First-trimester maternal plasma cell-free fetal DNA and preeclampsia," American Journal of Obstetrics and Gynecology, vol. 201, no. 5, pp. 472.e1-472.e7, 2009.

[87] X. Y. Zhong, W. Holzgreve, and S. Hahn, "The levels of circulatory cell free fetal DNA in maternal plasma are elevated prior to the onset of preeclampsia," Hypertension in Pregnancy, vol. 21, no. 1, pp. 77-83, 2002.

[88] R. J. Levine, C. Qian, E. S. Leshane et al., "Two-stage elevation of cell-free fetal DNA in maternal sera before onset of preeclampsia," American Journal of Obstetrics and Gynecology, vol. 190, no. 3, pp. 707-713, 2004.

[89] B. G. Zimmermann, D. G. Maddocks, and N. D. Avent, "Quantification of circulatory fetal DNA in the plasma of pregnant women," Methods in Molecular Biology, vol. 444, pp. 219-229, 2008.

[90] D. W. Swinkels, J. B. de Kok, J. C. M. Hendriks, E. Wiegerinck, P. L. M. Zusterzeel, and E. A. P. Steegers, "Hemolysis, elevated liver enzymes, and low platelet count (HELLP) syndrome as a complication of preeclampsia in pregnant women increases the amount of cell-free fetal and maternal DNA in maternal plasma and serum," Clinical Chemistry, vol. 48, no. 4, pp. 650-653, 2002.

[91] A. Farina, A. Sekizawa, M. Iwasaki, R. Matsuoka, K. Ichizuka, and T. Okai, "Total cell-free DNA ( $\beta$-globin gene) distribution in maternal plasma at the second trimester: a new prospective for preeclampsia screening," Prenatal Diagnosis, vol. 24, no. 9, pp. 722-726, 2004.

[92] A. Sekizawa, A. Farina, K. Koide et al., " $\beta$-globin DNA in maternal plasma as a molecular marker of pre-eclampsia," Prenatal Diagnosis, vol. 24, no. 9, pp. 697-700, 2004.

[93] S. Grill, C. Rusterholz, R. Zanetti-Dällenbach et al., "Potential markers of preeclampsia-a review," Reproductive Biology and Endocrinology, vol. 7, article 70, 2009. 

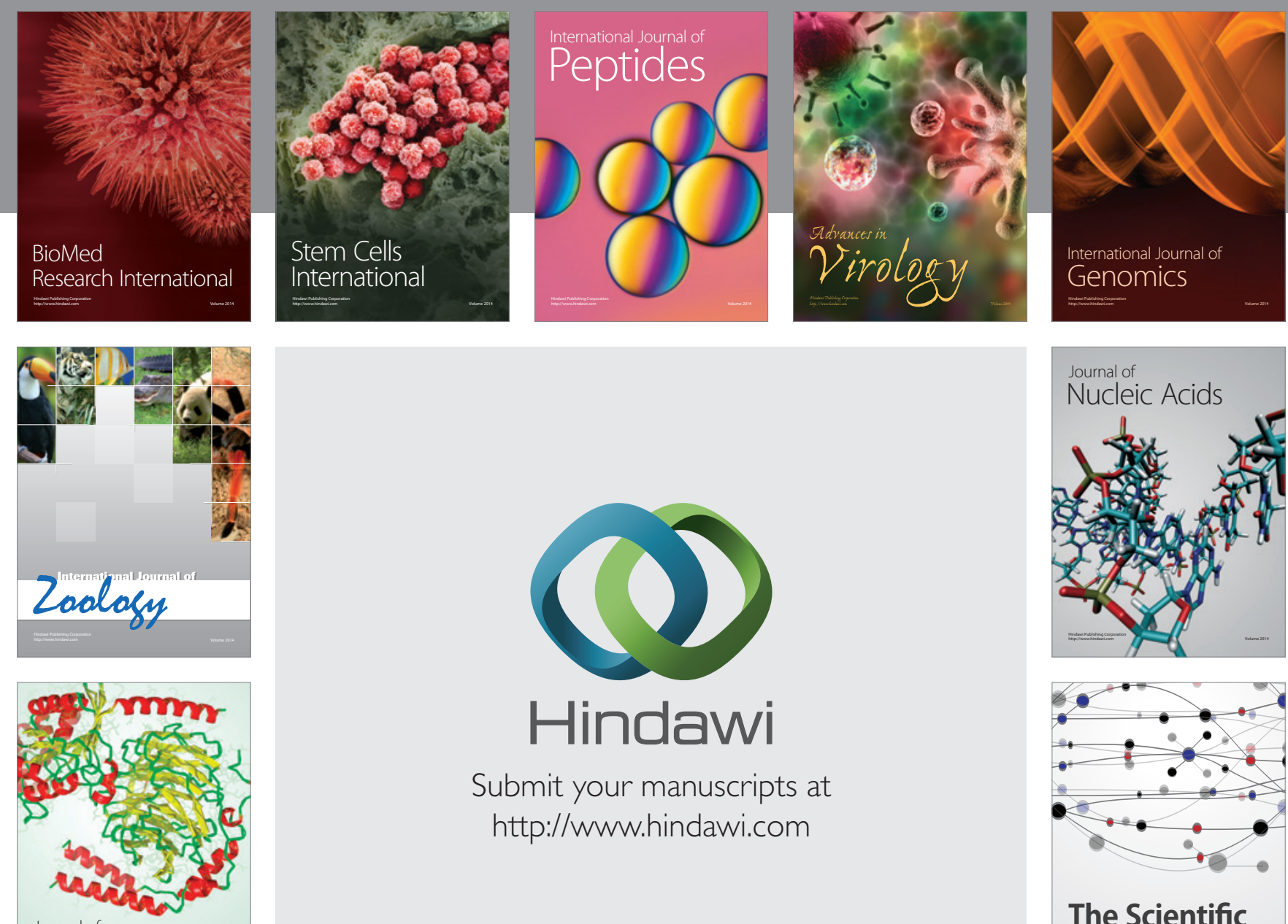

Submit your manuscripts at

http://www.hindawi.com

Journal of
Signal Transduction
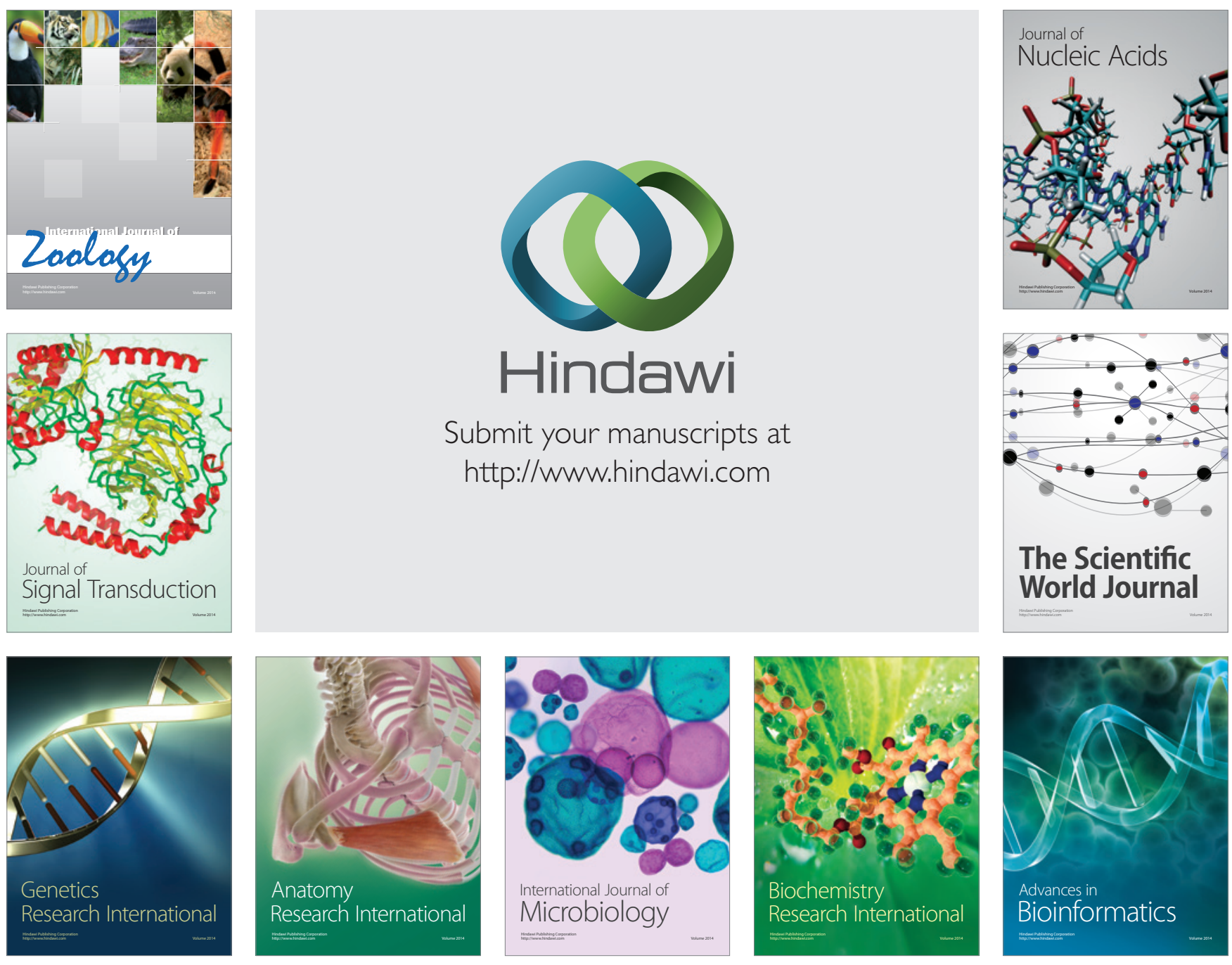

The Scientific World Journal
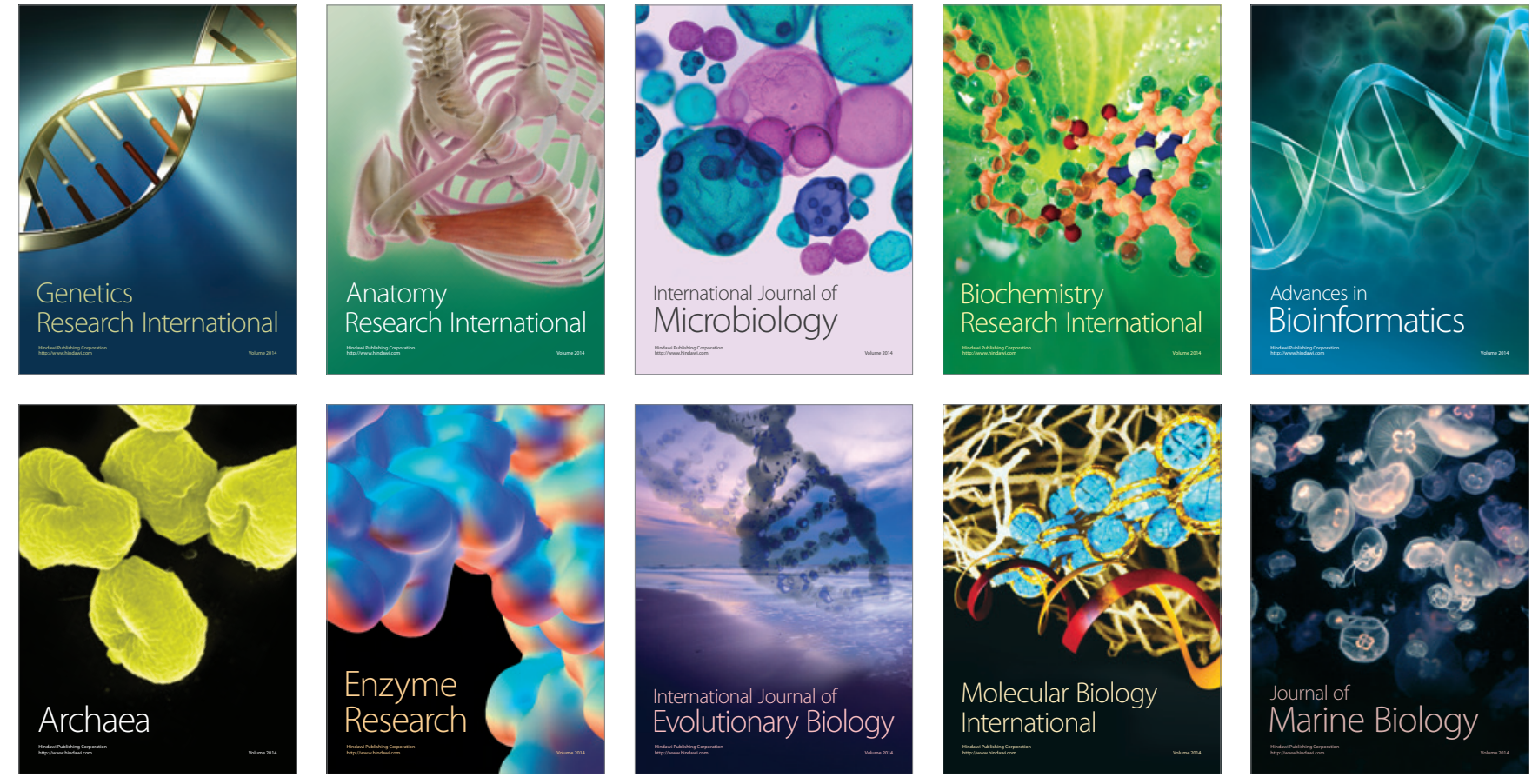